\title{
Solving electric grid network congestion problem with batteries-An exploratory study using GIS techniques
}

\author{
Vivian Sultan \\ Claremont Graduate University, Claremont, USA \\ California State University, Los Angeles, USA
}

\begin{abstract}
The United States electric utility industry is transitioning from a one-way distribution grid to a new power grid that can accommodate bidirectional energy flow. Utility companies desire a solution for electric grid traffic congestion, which will work in harmony with the industry's transition toward future integrated distribution systems. This shift in the complexity on the supply side, combined with the unpredictable fluctuations in the demand side, gives rise to the electric grid network congestion problem, resulting in unpredictable or planned outages.

In recent times, the advent of mega-size lithium-ion batteries has proven to be size- and cost-efficient to absorb and smoothen out such varying levels of demand on the supply side, thereby effectively addressing congestion problems. However, the networks are diverse in size and complexity: for any given network, one needs to determine the optimal number and location of such battery storage farms within the network. This report explores how Geographic Information Systems (GIS) can be used to effectively determine the optimal locations of such battery farms in resolving the electric grid traffic congestion problem.
\end{abstract}

Keywords: Smart grid, DERs, battery storage, circuit capacity, optimal location

\section{Introduction}

America's electric utility industry is transitioning from a one-way distribution grid to a new power grid that can accommodate two-way flow of energy. The current electric grid is viewed as a network for transporting electricity from power suppliers to individual consumers. Power generation is centralized to allow customers to purchase electricity from an electric utility company. This existing one-way power generation and distribution paradigm is no longer sustainable; electric distribution cannot meet the current demand for cleaner power, flexible choices, and more customer control on energy bills [1]. Furthermore, a one-way power grid cannot accommodate the increase in penetration of Distributed Energy Resources (DERs), such as solar rooftops and electric vehicles [2].

In August 2014, California Public Utilities Commission, the state regulatory body responsible for electric utilities, called for the integration of DERs into the electric distribution system. Subsequently, in February 2015, the Commission issued a Distribution Resources Plan (DRP) ruling to transform the current electric distribution system into a new system, which allows for two-way energy flow between customers and their respective utility companies [3]. The fundamental reason for the DRP ruling is to permit customer involvement and choice of newer technologies for power generation, transmission, and consumption [2].

Within the electric utility industry, technologies for solar, wind, and hydro-energy generation have made great progress in the past few years [4]. However, to a large extent, progress in the development of electric transmission and distribution systems has remained stagnant. Matching supply and demand across the power grid has become a challenge, while electric grid traffic congestion is surging. According to

\footnotetext{
* Manuscript received January 29, 2018; revised April 20, 2018.

Corresponding author. E-mail address: vivian.sultan@cgu.edu.

doi: 10.12720/sgce.7.2.117-124
} 
2015 United States Department of Energy (DoE) assessments, the electric power system in the United States is facing difficulties due to changes in both supply and demand technologies. A superior system for matching supply and demand is needed for electric power, especially due to the increased penetration of DERs [5].

The DoE Office of Science calls for research to assist the utility industry in its transition to a 21 st century grid. In response to these calls, this paper addresses the following question: "To what extent can Geographic Information Systems (GIS) be employed to resolve the electric grid traffic congestion problem"? The intent is to explore GIS, a class of tools for developing better models, and to propose a GIS-driven solution for the utility industry to resolve the electric grid traffic congestion problem. The intended audience for this research is state-level decision-makers, utility corporations, and other stakeholders concerned about the electric power system within the United States.

\section{Problem Background and Foundation}

The existing power grid is incapable of integrating DERs due to its lack of energy storage capabilities and its inefficiencies in transporting additional energy [5]. The current electric power paradigm in the United States cannot appropriately deal with the fluctuation in energy supply and demand; certain locations over-utilize their electricity, while other regions under-utilize their resources. Americans pay higher electricity bills when utility companies must procure energy from expensive sources in order to meet peak demands of excessive energy-consuming communities [6].

According to the national electric transmission congestion study, 2015, the term congestion is defined as a situation where transmission constraints reduce transmission flows or throughput below levels desired by market participants or government policy. Electric congestion happens as electricity flows over the transmission lines [7]. The adoption of distributed generated resources within the electric power grid leads to an increase in power constraints and electric transmission congestion [8]. Many factors contribute toward this problem, such as increased power generation from renewables in distant locations and the growing penetration of DERs [7].

The utility industry aims to transform the classic network topology to a grid that accommodates various DERs. The DoE has defined a smart grid as a new class of technology, which — using computerbased remote automation - will bring the electricity delivery system into the 21 st century (2015). The network technologies are the backbone of this system that allows two-way energy flow between the suppliers and consumers. The characteristic benefits of this new grid include customer participation in distributed energy generation, optimization of energy resources, improvement of power quality, and, ultimately, electricity cost reduction [9].

The power grid of the 21 st century must be adaptable, strong, and responsive to accommodate the addition of customers' lightweight generation resources and the integration of DERs. The electric power research institute estimates that in the next two decades, around \$338-\$476 billion will be incorporated in DERs, intelligence technologies, advanced systems, and applications for the utilities' new grid [5]. Tools for optimizing grid operations and to forecast future problems are crucial within a modern grid design. Forecasting tools to manage the supply and demand of electric power are essential for the utility industry to resolve potential grid traffic congestions.

According to DoE Quadrennial Technology Review, 2015, "the world of energy-related research is rich with opportunities to help create a secure, resilient, economically efficient, and environmentally responsible set of energy systems." The research community must take advantage of this opportunity and consult energy officials for a revolution in the electric power system in the United States [10]. In the next section of this paper, a GIS model design will be discussed. The model illustrates a GIS solution prototype that I have developed in an attempt to assist utilities providers in their efforts to resolve the electric grid congestion problem. 


\section{Model Design}

According to Bollen, M.H.J. \& Etherden, N., 2011, "under the current circumstances, the hosting capacity for DERs identifies the degree of DERs in the power grid that can be accepted without endangering the reliability or quality of power" [11]. The effect of DERs producing energy is the only element considered in the proposed model that can impact the hosting capacity of the distribution grid. Thus, an electric vehicle - a DER that consumes energy - will have zero impact in this case. DER hosting capacity (dependent variable) is determined by a number of independent variables, such as the voltage class of a distribution circuit, distance from the source substation, and rating of the equipment in the area.

DER hosting capacity represents the supply side of the equation. I posit that, ceteris paribus, DER hosting capacity available on the distribution network is solely reliant on the nominal voltage of the electric circuit. A higher voltage class will lead to a higher level of DER hosting capacity.

On the demand side, consumers' expenditure on electricity can be used as an indicator to locate areas where consumers are more likely to acquire private sources of electricity generation. The GIS solution proposed in this paper forecasts potential hot spots for congestion where a higher voltage class is needed to satisfy the demand for higher hosting capacity. GIS offers a framework for optimizing grid operations by balancing the supply and demand of electric power. This model can assist utility companies in prioritizing locations needing additional voltage and detecting regions where DERs may provide an overall benefit.

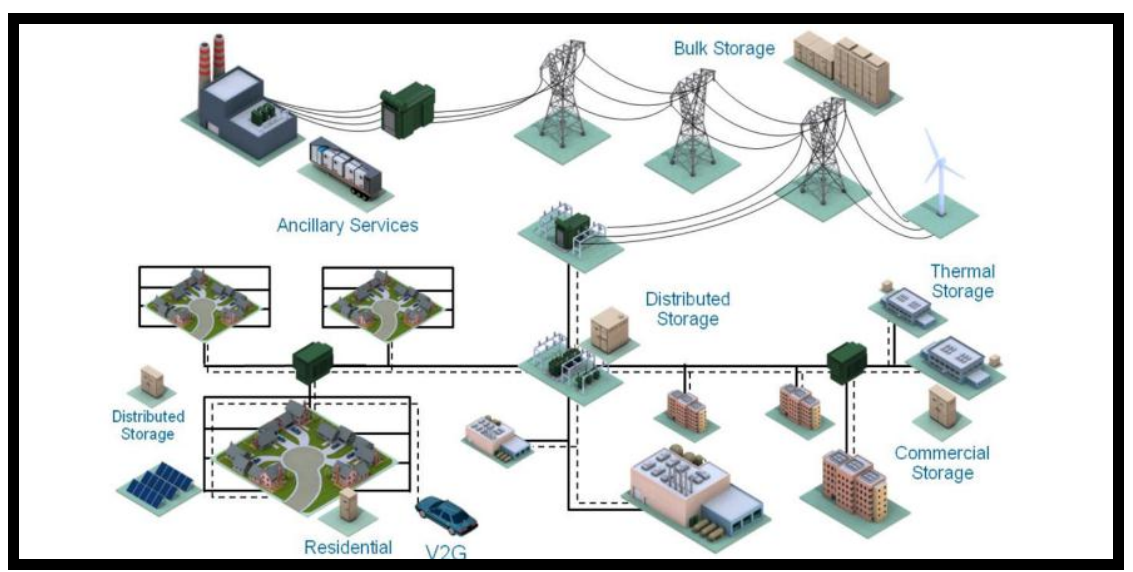

Fig. 1. Overview of energy storage roles on the electric grid [12]

In this paper, I discuss energy storage systems since earlier literature showed insufficient attempts by researchers to provide solutions that can assist in integrating storage systems into the grid. Considering that energy storage is a critical component to be added to the power network and the urgency of energy storage deployment, this paper addresses the manner in which we can determine the optimal locations of energy storage for proper integration into the electricity system.

GIS provides the tools and integration capability to support a smart grid. GIS can be used to highlight optimal locations for different components within the network. With the rollout of a smart grid, utilities need "to determine the right location for sensors, communication-marshaling cabinets, and a host of other devices" [13] (p.4). GIS provides the proper instruments to perform these design services, especially as the optimal locations greatly depend on the existing infrastructure. Considering the GIS' current role in managing the electric grid and previous research attempts, I posit that GIS will play an important role in the placement of smart grid components such as battery storage systems. GIS can certainly contribute toward the transformation of the grid "from a largely passive and blind system to an interactive, intelligent one" [13] (p.6).

Hence, the objective of this research is to develop a prototype of a GIS-based decision support system solution, which is an elegant, interesting, and novel solution to assist with the placement of battery 
storage systems by finding optimal locations considering electric grid constraints, deployment requirements, and potential benefits to the grid. The paper is based on the process steps mentioned in Takeda, et al.'s design cycle to create an artifact/solution [14]. I have used the three design science research cycles of relevance, design, and rigor [15] to perform each of Takeda, et al.'s process steps leading to the final framework and prototype in this paper.

Takeda, et al.'s (1990) cycle has five main steps/phases, namely, the awareness of the problem, suggestion, development, evaluation, and conclusion [14]. This paper is organized based on these five phases. In the introduction and literature review section, I discussed the awareness of the problem. In the conceptual framework and prototype sections, I covered the suggestion phase by explaining the decisions that I have made to develop the artifacts. I have indicated the steps taken to develop and create the artifacts as outlined in the development phase. In the evaluation section of the paper, I evaluated the artifacts. In the last section, I concluded my research and offered future research directions.

\section{Artifact 1: Conceptual Framework}

I have used and studied the background literature as a research method to develop the conceptual framework for decision-making that caters to utilities since it considers the impact of energy storage placement on the grid and the electric circuit capacity constraints, as shown in Fig. 2.

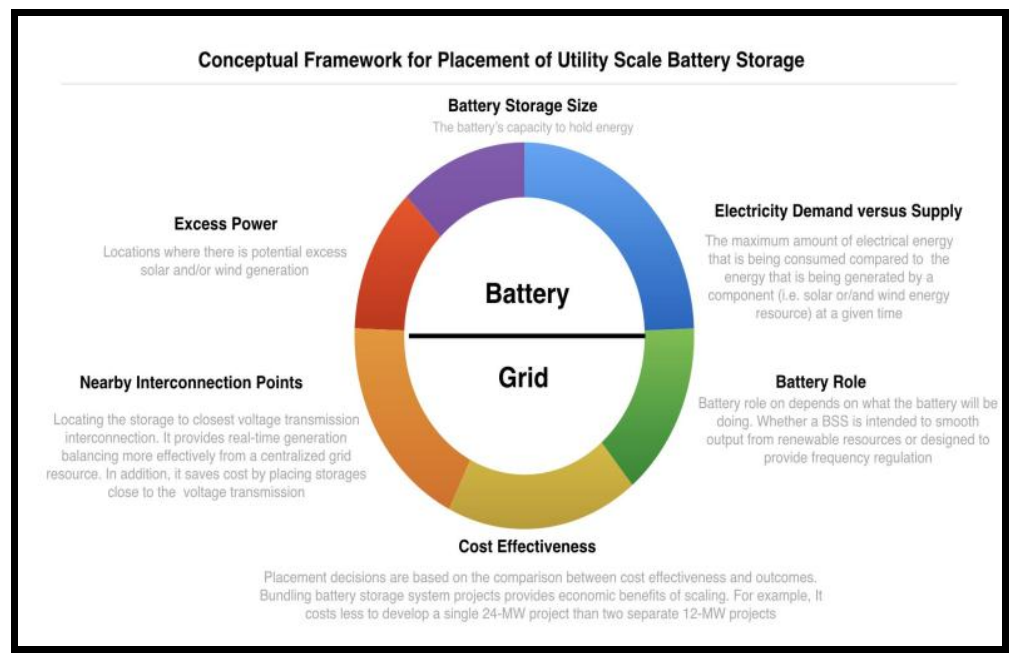

Fig. 2. Conceptual framework for the placement of utility-scale battery storage

My framework has two main dimensions. The first one is the factors' characteristic dimension, which has two main values: (1) battery and (2) grid. The second dimension is the factors that help in decisionmaking for the optimal location of battery storage. First, I searched in the literature, revealing three factors that relate to the battery. Then, I considered three more factors that relate to the grid. These factors assist in determining the optimal battery storages locations for utilities.

\section{Artifact 2: GDSS Prototype}

This study proposes a GDSS solution to assist in the placement of battery storage systems by finding the optimal locations considering electric grid constraints, deployment requirements, and potential benefits to the grid. This solution can aid in choosing battery storage system locations and provide actionable information for utilities, state-level decision-makers, and other stakeholders who are concerned about grid reliability and urgency of energy storage deployment as a DER. Although a GDSS can provide a solution to address the placement of all types of energy storage systems, I chose to focus on utility-scale storage to instantiate the conceptual framework and to demonstrate how an interactive, computer-based 
system can assist in decision-making, considering the overall potential benefits to the grid. The following are the data sources for the artifact:

$>$ Southern California Edison's (SCE's) DERiM Circuit Capacity Data: SCE's DER interconnection map includes power electric lines and capacity analysis in kilowatts by circuit line. The data is retrieved from DERiM's Web site: https://www.arcgis.com/home/item.html

$>$ Solar Parcel Data: LA County is the data source for the solar parcel data, available at http://solarmap.lacounty.gov/. LA County's solar map includes key data elements such as total roof area and area suitable for solar applications, potential solar system size, solar potential annual output, and potential cost savings.

$>$ Electricity Household: SimplyMap is the source of these data. The Electricity Household denotes the average of the annual (yearly) consumption in dollars for each geographic region in 2016. Electricity is generally supplied by means of above- or underground electric power lines.

My prototype suggested 12 potential battery storage locations in SCE's electrical substations based on three spatial factors in the conceptual framework: 1) demand vs. supply, 2) nearby interconnection points, and 3) excess power. The locations are listed in Table 1 and shown in Fig. 3.

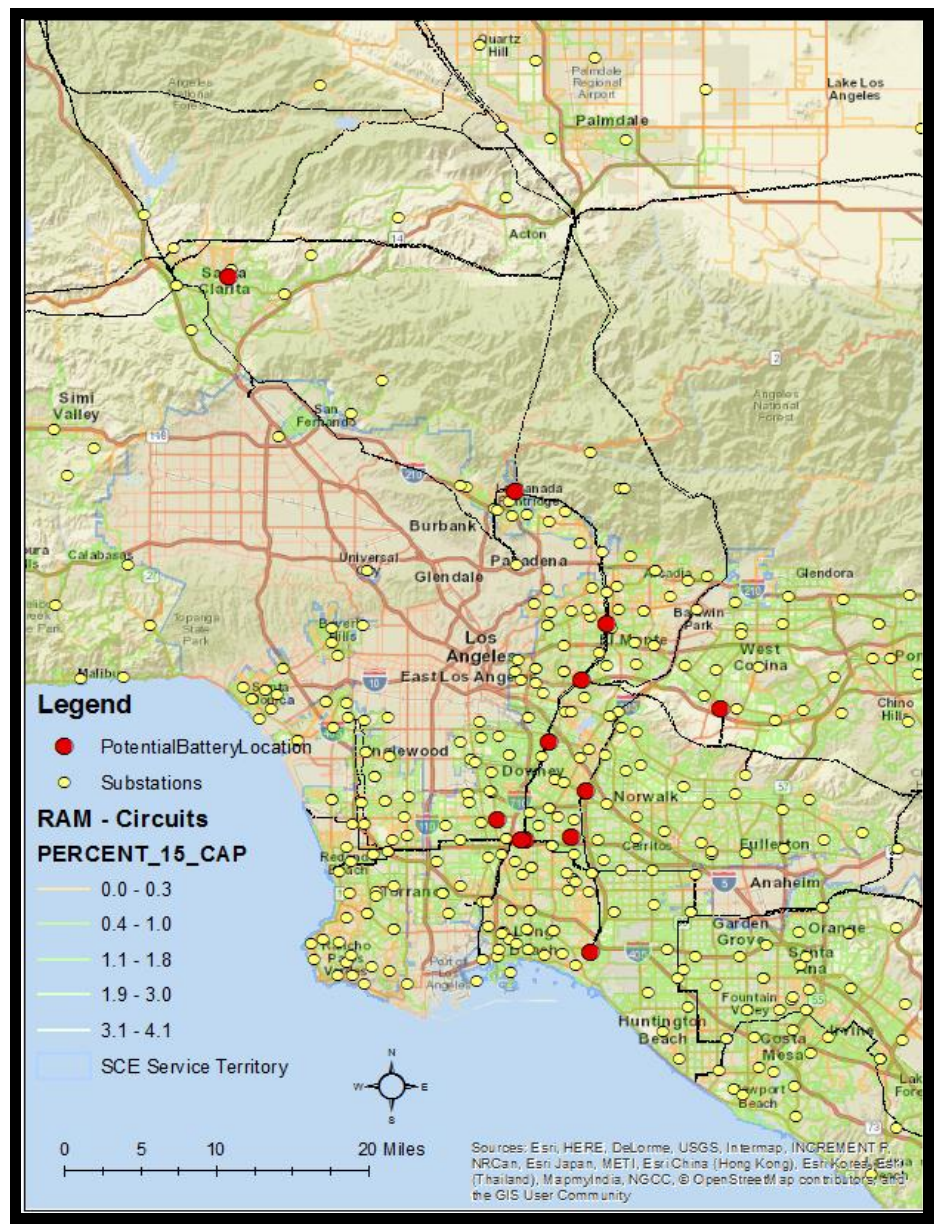

Fig. 3. Suggested battery storage locations 
Table 1 . List of potential battery storage locations

\begin{tabular}{ccc}
\hline ID & Substation Name & Substation Type \\
\hline 1 & WALNUT & S -- Sub-transmission \\
2 & ROSEMEAD & D -- Distribution \\
3 & GOULD & S -- Sub-transmission \\
4 & MESA & S -- Sub-transmission \\
5 & LAGUNA & S -- Sub-transmission \\
6 & BULLIS & D -- Distribution \\
7 & CENTER & S -- Sub-transmission \\
8 & CORNUTA & D -- Distribution \\
9 & LIGHTHIPE & S -- Sub-transmission \\
10 & SUNLIGHT P.T. & A -- District Pole Top \\
11 & HASKELL & D -- Distribution \\
12 & STADIUM & D -- Distribution \\
\hline
\end{tabular}

According to Jim Horstman, an industry consultant, the pole top substation (Sunlight P.T.) (Table 1) might not be used for batteries, as this "substation" is built on a platform between poles. Thus, I have a final count of 11 potential battery storage locations after excluding the pole top substation.

\section{Evaluation}

I have applied a qualitative interview method to evaluate my prototype using a socio-technical technique in order to assess the following metrics: propriety and utility. In this case, both EV drivers' and utility executives' perspectives were considered in the evaluation process in order to ensure that their unique stances were understood. I evaluated the different values concerning utilities by sending the following interview questions via e-mail:

1. How useful is the conceptual framework (Fig. 2) in your view?

2. Is the framework complete from your perspective?

3. Do you see a potential solution offered by the GDSS prototype (Fig. 3)?

4. What changes would you recommend for improvement?

5. Do you see potential in this research direction?

Feedback is currently being solicited from industry consultants and executives who can provide feedback from a utility perspective. Two participants responded with positive feedback, and they highlighted the potential offered by the proposed artifact. According to Jim Horstman, the conceptual framework is useful, complete, and covers the relevant issues. Horstman mostly agreed with the factors' definitions. However, he suggested that the framework dimensions were confusing. He stated that "the battery factor is related to the grid rather than the battery, and the excess power and supply and demand factors are related to the battery when it seemed more appropriate to relate it to the grid. Further, excess power is a function of supply and demand (i.e., excess power occurs when supply exceeds demand); therefore, it is unclear whether it is a separate issue or not." The industry consultant suggested another consideration with regard to nearby interconnection points, which denotes the space available for battery storage. "While many substations might have ample space for batteries, others may have restraints," he said.

Horstman agreed with the technical specifications with the exception of including specific voltages (154 KV and $345 \mathrm{KV}$ ) since "these are utility specific, e.g., SCE could be 220/500 KV for high voltage subs, where it is stepped down to $133 \mathrm{KV}, 66 \mathrm{KV}$, etc." The industry consultant recommended something more appropriate like high- and medium-voltage substations. With reference to Table 1, Jim Horstman saw that it includes sub-transmission and distribution substations that he believes would be categorized as medium and/or low voltage. 


\section{Conclusion}

The artifacts proposed in this paper aimed at providing a solution for decision-making in order to assist with the placement of battery storage systems by finding optimal locations considering electric grid constraints, deployment requirements, and potential benefits to the grid. This could potentially save time and resources for developers and utility companies who are interested in the identification of optimal locations for the placement of storage systems. Potential locations for battery storage can, therefore, be prioritized in locations with excess power, where supply of electricity is actually more than the demand level and where there is nearby a substation territory.

The utility and novelty of the solution is important to emphasize as the driving factors for this project. By developing a conceptual framework for decision-making that previously did not exist, a large amount of time is reduced for utilities/grid operators who are interested in finding optimal locations and integrating storage systems into the grid. The GDSS prototype can be regarded as an instantiation (to provide an instance of or concrete evidence in support) of the conceptual framework. Therefore, it is important to realize that this prototype is only meant to serve as a good starting point for the illustration of how an interactive, computer-based system can assist in decision-making considering the overall potential benefits to the grid.

From this research, I conclude that GIS can be used to effectively determine the optimal locations of battery farms in resolving the electric grid traffic congestion problem. Battery storage locations can be assessed geographically to minimize potential increases to the overall electric system costs while still meeting customers' needs. My solution provides evidence that GIS can play an integral role in problem resolution.

\section{Acknowledgments}

I would like to acknowledge the efforts of Dr. Brian Hilton who provided insightful comments and helped me with the project analysis. Also, I would like to thank Mr. Warren Roberts and the group working at CGU GIS lab for their support.

\section{References}

[1] United States Department of Energy: Office of Electricity Delivery and Energy Reliability. (2015a). Smart Grid. Retrieved. [Online]. Available: http://energy.gov/oe/services/technology-development/smart-grid

[2] Gergen M, Campopiano M, Meyer A. (2014). CPUC Opens Rulemaking to Incorporate Distributed Energy Resources Into Grid Planning Process for California's Investor-Owned Utilities : Clean Energy Law Report: Renewable Energy Lawyer and Environmental Law Attorney: Latham \& Watkins Law Firm. [Online]. Available: http://www.cleanenergylawreport.com/finance-and-project-development/cpuc-opens-rulemaking-to-incorporate-distributedenergy-resources-into-grid-planning-process-for-cal/

[3] California Public Utility Commission (2015a). Distribution Resources Plan. [Online]. Available: http://www.cpuc.ca.gov/PUC/energy/drp/index.htm

[4] United States Department of Energy: Office of Electricity Delivery and Energy Reliability. (2015b). What is Renewable Energy. [Online]. Available: https://www.smartgrid.gov/the_smart_grid/renewable_energy.html

[5] United States Department of Energy. (2015d). Quadrennial Technology Review: An Assessment of Energy Technologies And Research Opportunities: Chapter 3-Enabling Modernization of the Electric Power System. [Online]. Available: http://energy.gov/downloads/chapter-3-enabling-modernization-electric-power-system

[6] Investopedia. (2015). The Industry Handbook: The Utilities Industry. [Online]. Available: http://www.investopedia.com/features/industryhandbook/utilities.asp

[7] United States Department of Energy. (2015c). National Electric Transmission Congestion Study. [Online]. Available: http://energy.gov/oe/downloads/2015-national-electric-transmission-congestion-study

[8] Diesel Service \& Supply. (2015). Electric Power Grid Modernization and Expansion. [Online]. Available: http://www.dieselserviceandsupply.com/Power_Grid_Upgrades_and_Expansion.aspx

[9] United States Department of Energy. (2015f). Smart Grid. [Online]. Available: http://energy.gov/science-innovation/electricpower/smart-grid 
[10] United States Department of Energy. (2015e). Quadrennial Technology Review: Executive Summary. [Online]. Available: http://energy.gov/downloads/executive-summary

[11] Bollen MHJ, Etherden N. (2011). Increasing the hosting capacity of distribution networks by curtailment of renewable energy resources. [Online].

Available: https://www.researchgate.net/publication/224258409_Increasing_the_hosting_capacity_of_distribution_networks_by_curtailm ent_of_renewable_energy_resources

[12] Kamath, Haresh (2013). Environmental Systems Research Institute. Electricity Storage in Utility Applications. [Online]. Available: https://www.usea.org/sites/default/files/event-/EPRI Storage Presentation - USEA - 13 September 2013.pdf (accessed on February 22 2017).

[13] Environmental Systems Research Institute. Enterprise GIS and the Smart Electric Grid. [Online]. Available: https://www.esri.com/library/whitepapers/pdfs/enterprise-gis-smart-electric-grid.pdf (accessed on 5 February 2017).

[14] Takeda H, Veerkamp P, Yoshikawa H. Modeling design process. AI Magazine, 1990; 11(4): 37.

[15] Hevner A. A three-cycle view of design science research. Scandinavian Journal of Information Systems. 2007; 19(2): 87-92. 